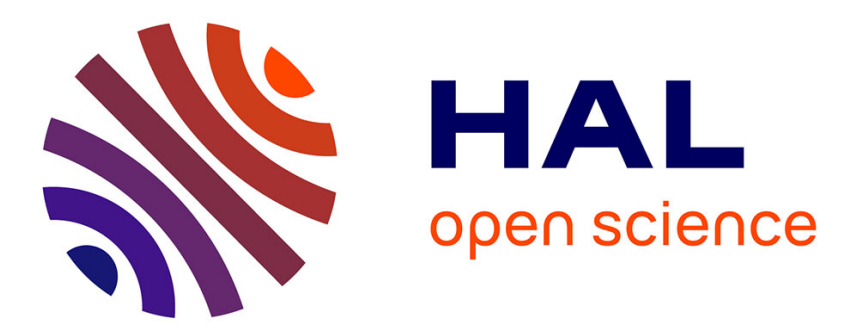

\title{
Synthesis and characterization of tetrathiol-substituted double-decker or ladder silsesquioxane nano-cores
}

Yujia Liu, Mana Kigure, Riho Okawa, Nobuhiro Takeda, Masafumi Unno, Armelle Ouali

\section{- To cite this version:}

Yujia Liu, Mana Kigure, Riho Okawa, Nobuhiro Takeda, Masafumi Unno, et al.. Synthesis and characterization of tetrathiol-substituted double-decker or ladder silsesquioxane nano-cores. Dalton Transactions, 2021, 50 (10), pp.3473-3478. 10.1039/d1dt00042j . hal-03193907

\section{HAL Id: hal-03193907 \\ https://hal.umontpellier.fr/hal-03193907}

Submitted on 11 Nov 2021

HAL is a multi-disciplinary open access archive for the deposit and dissemination of scientific research documents, whether they are published or not. The documents may come from teaching and research institutions in France or abroad, or from public or private research centers.
L'archive ouverte pluridisciplinaire HAL, est destinée au dépôt et à la diffusion de documents scientifiques de niveau recherche, publiés ou non, émanant des établissements d'enseignement et de recherche français ou étrangers, des laboratoires publics ou privés. 
Received 00th January 20xx, Accepted 00th January 20xx

\section{Synthesis and Characterization of Tetrathiol-substituted Double- Decker or Ladder Silsesquioxane Nano-Cores}

\author{
Yujia Liu, ${ }^{a}$ Mana Kigure, ${ }^{b}$ Riho Okawa, ${ }^{b}$ Nobuhiro Takeda, ${ }^{b}$ Masafumi Unno, ${ }^{a, b}$ Armelle Ouali* ${ }^{a, c}$
}

DOI: $10.1039 / x 0 \times x 00000 x$

Tetra(3-mercaptopropyl)-silsesquioxanes with double-decker (DDSQ) or ladder nano-cores were easily prepared from the corresponding tetraallyl derivatives through fast and convenient thiol-ene reactions. An additional tetrathiol-DDSQ with more flexible arms was also synthesized in high yield from the corresponding tetrachloro-DDSQ derivative. The three novel tetrathiol silsesquioxanes described represent versatile building blocks for the preparation of hybrid organic-inorganic materials.

Hybrid molecules combining the thermostability of inorganics and the chemical flexibility of organics at the nanometer scale attract growing interest in various areas of chemistry. Along these lines, polyhedral oligomeric silsesquioxanes (POSSs) composed of an inner rigid inorganic $\mathrm{Si}-\mathrm{O}-\mathrm{Si}$ core surrounded by organic reactive groups constitute a versatile platform to design various types of functional hybrid materials. ${ }^{1-3}$ Among them, the cubic silsesquioxanes ( $T_{8}$-cages) have been widely studied and shown to have a great potential in numerous fields including catalysis, ${ }^{4}$ photoactive materials, ${ }^{5}$ nanocomposites based on POSS and biomass ${ }^{6}$ or coating materials ${ }^{7}$ to name a few. ${ }^{7-9}$ Among functionalizable $T_{8}$-cages, those decorated with thiol functions revealed key building blocks to design multifunctional materials. Indeed, the $\mathrm{SH}$ group can react with readily available olefins through thiol-ene reactions that are expedited synthetic processes with quantitative yields and short reaction times. ${ }^{10}$ These "click reactions" occur in the presence of a radical initiator and/or upon irradiation.

Although the preparation of mono- or di-substituted cages bearing one (or two) SH function(s) have been reported, their application seems still limited. ${ }^{11-13}$ On the contrary, the related octathiol $\mathrm{T}_{8}$ cage $^{14,15}$ received great attention. ${ }^{16-62}$ Indeed, the presence of several reactive thiol groups confers multivalency

\footnotetext{
${ }^{a .}$ Gunma University Initiative for Advanced Research (GIAR)-International Open Laboratory with ICGM France and ${ }^{b .}$ Department of Chemistry and Chemical Biology, Graduate School of Science and Technology. Gunma University, Kiryu 376-8515, Japan

ICGM, Univ Montpellier, CNRS, ENSCM, Montpellier 34296, France.

Electronic Supplementary Information (ESI) available: [details of any supplementary information available should be included here]. See DOI: 10.1039/x0xx00000x
}

that constitutes a crucial parameter in many applications. For example, octathiol- T $_{8}$-POSS has been used as dendrimers cores $^{16}$ to reach molecular materials relevant in the fields of energy ${ }^{17}$ or optics. ${ }^{18}$ Multivalency is also a strong asset in the field of nanomedicine. ${ }^{19,20}$ The octathiol POSS was also used to access disulfide-based organic/inorganic hybrid dynamic networks with self-healing ${ }^{21}$ or sensing ${ }^{22}$ properties. In most of the reported cross-linked systems, the vertices of the cage are connected by polymers chosen depending on the targeted application. ${ }^{23-48}$ The POSS units confer high thermal and mechanical stabilities to the corresponding hybrid materials that find applications in areas as diverse as UV-curable nanocomposite coatings, hydrogels for tissues engineering scaffolds, conducting elastomers for lithium batteries, chromatography or sensing. ${ }^{23-48}$ Most of these hybrids were prepared through thiol-ene photopolymerization that constitutes an attractive alternative technology since faster than sol-gel chemistry, free radical or ring-opening polymerization and less sensitive towards oxygen. ${ }^{48}$ Besides, POSSs cores have been shown to be important building blocks to construct and drive the assembly of amphiphilic hybrid POSSs. ${ }^{49}$ The outstanding properties of the resulting materials find their origin in the self-organisation of the molecular fragments including the inorganic $\mathrm{T}_{8}$-head and the organic tails. Along these lines, octathiol- $\mathrm{T}_{8}$-POSSs occupy a key place and were functionalized with hydrophilic ${ }^{50-53}$ or hydrophobic fragments ${ }^{54-59}$ to reach materials employed for sensing, in photocurable systems. or for preparing hybrid microcapsules. ${ }^{60-61}$ Also, carbazole substituted T8-POSSs prepared from the corresponding thiol derivatives and 9vinylcarbazole exhibit very good thermal, mechanical and photochemical properties. ${ }^{62}$ To sum up, the versatility offered by reactive thiol groups present on each corner of $\mathrm{T}_{8}$-POSS gave rise to a feature-rich platform opening opportunities in various application fields. Given the increasing interest of hybrid materials with good mechanical and thermal properties in science and industry, the design of functionalizable POSSs with different topological structures appears as a research hotspot. Indeed, varying the number of reactive groups and the inorganic core structure will give access to new nanocomposites displaying different properties. 


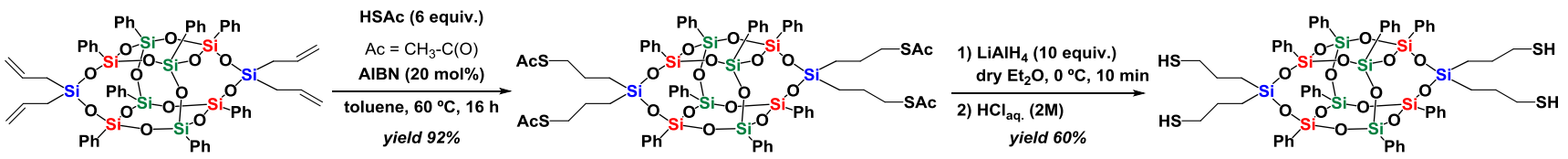

1

2 3

Scheme 1. Synthesis of the tetra-(3-mercaptopropyl)-DDSQ 3.

In this work, the synthetic routes to three unprecedented tetrathiol silsesquioxanes are described. Two of them are based on $\mathrm{D}_{2} \mathrm{~T}_{8}$-double decker silsesquioxane (DDSQ) structure and the third one involved ladder oligosilsesquioxanes with defined structures (called "laddersiloxanes"). The resulting compounds were prepared in fair to very good yields from inexpensive precursors and both DDSQ derivatives could be prepared in gram scale. These three functionalizable nanohybrids are complementary to those derived from the $T_{8^{-}}$ cage and are particularly relevant for preparing a wide range of materials.

Difunctional $D_{2} T_{8}$ and tetrafunctional $M_{4} T_{8}$ DDSQ bearing two or four functional groups respectively have been widely described and used to prepare various materials with appealing properties. ${ }^{63}$ More recently, we reported the first $\mathrm{D}_{2} \mathrm{~T}_{8}$ structures bearing four reactive substituents including vinyl, allyl, chloro, iodo or azido groups. ${ }^{64,65}$

a) DDSQ 3

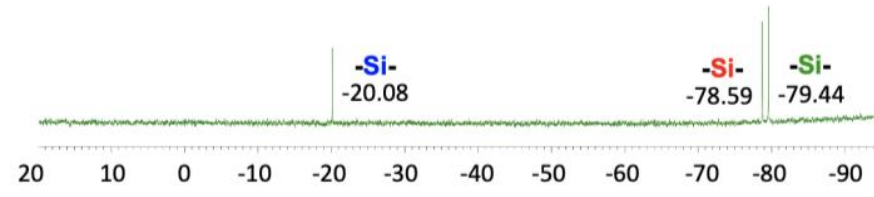

b) DDSQ 6

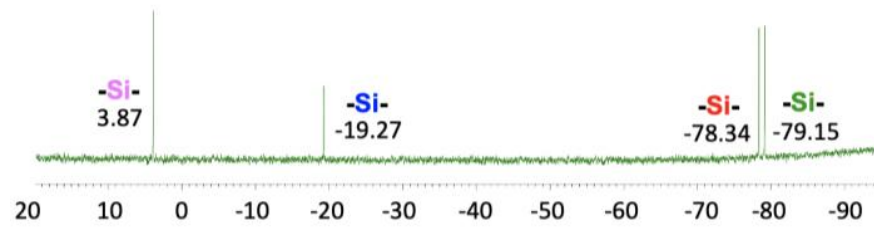

c) Laddersiloxane 9

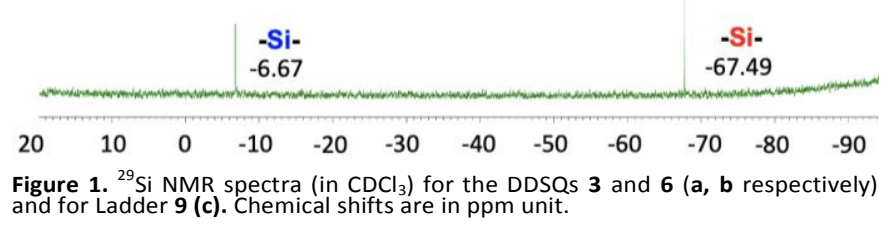

Therefore, the previously described tetraallyl-DDSQ 1 was allowed to react with thioacetic acid in the presence of AIBN as the radical initiator (Scheme 1). After $16 \mathrm{~h}$ at $60{ }^{\circ} \mathrm{C}$ in toluene, quantitative functionalization occurred and the expected tetrakis(3-propyl ethanethioate) derivative $\mathbf{2}$ could be isolated in $92 \%$ yield after washing crude product with hexane. On reduction with lithium aluminium hydride followed by workup with hydrochloric acid, the corresponding tetrathio-DDSQ 2 was isolated in $60 \%$ yield (Scheme 1). ${ }^{66}$ This yield could be improved to $65 \%$ by using 15 equivalents of $\mathrm{LiAlH}_{4}$ instead of 10 and by increasing the reaction time from 10 to 15 minutes. Compound $\mathbf{2}$ was characterized by multinuclear NMR and mass spectroscopies (see supporting information). The ${ }^{29} \mathrm{Si}$ spectrum of 3 (Figure 1a) displayed two singlets for the non-equivalent T-unit silicon atoms of the core.

The resonance at $\mathbf{- 7 9 . 4 4} \mathrm{ppm}$ was assigned to the internal Tgroup silicon atoms ( $\mathrm{Si}$ in green) and that at -78.59 was assigned to the T-group silicon atoms (red color) nearest to the D-group silicon atoms (blue color). The latter gave rise to a singlet at around $-20.08 \mathrm{ppm}$ consistent with chemical shifts previously reported for related $D_{2} T_{8}$-DDSQs with alkyl substituents. ${ }^{64,65}{ }^{1} \mathrm{H}$ NMR spectrum showed the four resonances expected for the mercaptopropyl substituents with chemical shifts and multiplicity in accordance with those reported for octa(3-mercaptopropyl)-silsesquioxane $\left(\alpha-\mathrm{CH}_{2}\right.$ (as compared to the D-group silicon atom) at $0.81 \mathrm{ppm}$; $\mathrm{SH}$ at 1.06 ppm appearing as a triplet $\left({ }^{3} \mathrm{~J}_{\mathrm{H}-\mathrm{H}}=7.9 \mathrm{~Hz}\right) ; \beta-\mathrm{CH}_{2}$ at $1.71 \mathrm{ppm}$ and $\gamma-\mathrm{CH}_{2}$ at $\left.2.41 \mathrm{ppm}\right) .{ }^{14,15}$ The data obtained from ${ }^{1} \mathrm{H},{ }^{13} \mathrm{C}$ NMR and MALDI-TOF mass spectroscopy were in accordance with the molecular structures (see supporting information).

Single crystals were grown and the structure of $\mathbf{3}$ determined by X-ray crystallography (Figure 2). This structure displays similar framework to the parent diallyl-DDSQ 1, with Si-O bond lengths in the ranges of 1.600(3)-1.633(3) $\AA$ (average 1.617(6) $\AA$ ) for 3 as compared to 1.607(9)-1.634(8) Å (average 1.619(9) $\AA)$ for 1 . Si-C lengths, in the ranges of 1.842-1.855 $\AA$ (average $1.848 \AA$ ) , were also consistent with those found for related compound 1 (in the ranges of 1.845(6)-1.869(2) $\AA$ (average $1.852(6) \AA)$ ). The $\mathrm{C}$-S lengths were found in the range of $1.807(3)-1.827(3) \AA$ (average $1.817(3) \AA$ ). Generally, the Si-O, $\mathrm{Si}-\mathrm{C}$ and $\mathrm{C}-\mathrm{S}$ bond lengths in $\mathbf{3}$ were comparable with those reported for the related octakis(3-mercaptopropyl)-T -POSS. $^{15}$ The internal Si...Si distances were also measured (see Table S2). The interatomic Si...Si distances were found in the range of 3.0984-4.6241 $\AA$ (average $3.3883 \AA$ ) for the o-Si...Si, 4.2069$5.2974 \AA$ (average $4.7371 \AA$ ) for the $m$-Si...Si and 5.0421$6.6830 \AA$ (average $5.8303 \AA$ ) for the $p$-Si...Si. These average values reported for related $T_{8}$-cages are found in the range of 3.11-3.16 $\AA, 4.40-4.45 \AA$ and 5.39-5.43 $\AA$ for the $o-, m$ - and $p$ Si...Si respectively. ${ }^{67}$ For the DDSQ cage $\mathbf{3}$, higher interatomic 
Si...Si distances and larger deviations are thus observed as compared to the $\mathrm{T}_{8}$-cage. These observations may be rationalized by the larger size and the enhanced flexibility of the DDSQ nanocore as compared to the rigid cubic cage. ${ }^{68}$ In addition, in 3, the $\mathrm{Si}-\mathrm{O}-\mathrm{Si}$ bond angles vary from 136.44 to $176.62^{\circ}$ which corresponds to the range encountered for 1 $\left(138.8(8)^{\circ}-166.3(7)^{\circ}\right)$ and previously reported DDSQ resulting from the hydrosilylation of the $C=C$ bond. ${ }^{64-65}$ The large deviation of the bond angles as compared to most of $\mathrm{T}_{8}$ scaffolds (standard deviation $<15^{\circ}$ ) indicates the flexible structure of the frameworks. ${ }^{1}$ In the case of the octathiol- $\mathrm{T}_{8}-$ cage, adjacent molecules were found to be associated in onedimensional supramolecular chains due to intermolecular SH...S hydrogen bonds. ${ }^{15}$ There are no remarkable intermolecular interactions in the crystal structure of $\mathbf{3}$, although some $\mathrm{C}-\mathrm{H} \bullet \bullet \cdot \mathrm{S}, \mathrm{C}-\mathrm{H} \bullet \bullet \bullet \mathrm{O}$, and $\mathrm{C}-\mathrm{H} \bullet \bullet \bullet$ distances are within the sum of van der Waals radii (see Table S3).

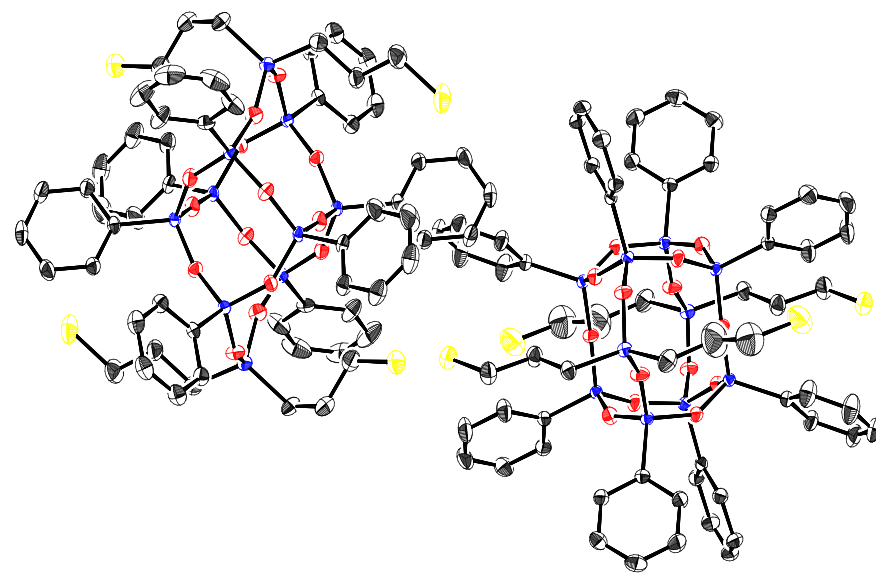

Figure 2. Crystal structure of tetra-(3-mercaptopropyl)-DDSQ 3. Black: carbon blue: silicon; red: oxygen; yellow: sulphur.

In an endeavour to access tetramercapto-DDSQ with longer arms and increased flexibility, previously described DDSQ 4 decorated with four chloro substituents and obtained quantitatively from 1 in one step ${ }^{65}$ was allowed to react with potassium thioacetate. The resulting tetra-thioacetate DDSQ 5 was isolated in $91 \%$ yield after $16 \mathrm{~h}$ at $22{ }^{\circ} \mathrm{C}$ (Scheme 2). ${ }^{69}$ DDSQ 5, prepared in gram scale, characterized by multinuclear NMR and mass spectroscopies (see supporting information) was used without further purification and converted into the expected tetra-mercapto-DDSQ 6 by using typical reducing conditions with lithium aluminium hydride (Scheme 2$).{ }^{66}$ DDSO 6 , obtained in $86 \%$ yield, was fully characterized. By ${ }^{29} \mathrm{Si}$ NMR and as for compound 3 (Figure 1b), the non-equivalent silicon atoms of the core gave rise to two distinct singlets at -79.15 ( $\mathrm{Si}$ in green) and -78.34 ( $\mathrm{Si}$ in red) ppm. The signal at $-19.27 \mathrm{ppm}$ was assigned to the external D-group silicon atoms ( $\mathrm{Si}$ in blue) while the singlet at 3.87 corresponded to the carbosilane ( $\mathrm{Si}$ in pink). The ${ }^{1} \mathrm{H}$ NMR spectrum displayed a triplet at $0.93 \mathrm{ppm}$ $\left({ }^{3} J_{\mathrm{H}-\mathrm{H}}=7.1 \mathrm{~Hz}\right)$ integrating for 4 protons that clearly showed the presence of the thiol SH groups. The four methylene groups gave rise to four resonances at $0.59,0.81,0.94$ and $1.41 \mathrm{ppm}$. Other analytical techniques including ${ }^{13} \mathrm{C} \mathrm{NMR \text {, }}$ elemental analysis and MALDI-TOF mass spectroscopy also confirmed the structure and the purity (see supporting information), with for example an experimental mass found at $1733.79 \mathrm{~g} . \mathrm{mol}^{-1}$ for $\left[\mathrm{M}+\mathrm{Na}^{+}\right]$in accordance with the calculated one at 1734.00 g.mol ${ }^{-1}$. Crystals could not be grown from 6 which is likely due to the inherent flexibility of this compound that was designed for this purpose. Moreover the carbosilane arms enabled to tune the solubility since 6 was more soluble in nonpolar solvents such as hexane or 1-hexene than the related (3-mercaptopropyl) derivative 3.

Given the importance and the versatility of the thiol reactive groups and in order to create novel polymercapto-POSS with different core structure, we next planned to prepare tetra(3mercaptopropyl)-laddersiloxanes. ${ }^{70-72}$ To this end, the previously described tetraallyl laddersiloxane $\mathbf{7}^{72}$ was quantitatively transformed into the corresponding tetrakis(3propyl ethanethioate) $\mathbf{8}$ derivative in the presence of thioacetic acid and AIBN as the radical initiator (Scheme 3 ). After washing the crude product with hexane, $\mathbf{8}$ was isolated in $91 \%$ yield, fully characterized and used without further purification in the next step. The latter, consisting in a reduction with lithium aluminium hydride followed by an acidic work-up, yielded the expected tetrathiol 9 in 38\% yield after column chromatography. The lower yield in the case of this ladder siloxane as compared to the DDSQ might be explained by the higher sensitivity of the core towards the reducing agent. Indeed, the temperature and reaction time had to be finely tuned to complete the deacetylation while limiting the degradation of the ladder framework. The use of milder reducing agents might enable to improve the yield. ${ }^{73}$

Multinuclear NMR spectroscopies were performed to characterize laddersiloxane 9. By ${ }^{29} \mathrm{Si}$ NMR spectrum (Figure 1c), the singlet corresponding to the T-group silicon atoms was found at $-67.49 \mathrm{ppm}$ ( $\mathrm{Si}$ in red). The ${ }^{29} \mathrm{Si}$ resonance at -6.67 ppm has been assigned to D-groups silicon atoms ( $\mathrm{Si}$ in blue) and this value was found to be consistent with the one reported for related ladder-like structures with four alkyl substituents and resulting for example from the hydrosilylation of 7 with dimethylphenylsilane. ${ }^{72} \mathrm{H}$ and ${ }^{13} \mathrm{C}$ NMR spectra were in accordance with the successful and quantitative reduction of the thioacetate groups. Compound $\mathbf{9}$ was also analyzed by MALDI-TOF mass spectroscopy and the experimental mass spectra (928.55 g.mol-1 for $\left[\mathrm{M}+\mathrm{Na}^{+}\right]$) was in good agreement with the calculated molecular weight (928.51 g.mol-1 for $\left.\left[\mathrm{M}+\mathrm{Na}^{+}\right]\right)$. Along the same lines, elemental analyses results matched very well to the theoretical values (see $\mathrm{SI}$ ).

Vibrational spectroscopy confirmed the presence of the characteristic strong Si-O-Si band occurring at ca. $1130-40 \mathrm{~cm}^{-1}$ for compounds $\mathbf{2}, \mathbf{3}, \mathbf{5}, \mathbf{6}, \mathbf{8}$ and $\mathbf{9}$ (see supporting information). In the FTIR spectra of tetra-thioacetate DDSQs $\mathbf{2 , 5}$ and $\mathbf{8}$, the strong band at 1691,1689 and $1700 \mathrm{~cm}^{-1}$ respectively were assigned to the $\mathrm{C}=\mathrm{O}$ vibration frequency of the thioacetate moiety. The absence of these bands in the FTIR spectra of DDSQs 3, 6 and $\mathbf{9}$ confirmed the successful deacetylation.

Thermogravimetric analyses (TGA) were performed under a $\mathrm{N}_{2}$ atmosphere and higher $\mathrm{Td} 5$ ( $5 \%$ weight loss) temperatures were obtained for compounds 3, 6 and $9\left(349,346\right.$ and $354{ }^{\circ} \mathrm{C}$ respectively, see Table S4) compared with that of the octathiol $\mathrm{T}_{8}\left(\mathrm{Td} 5=307{ }^{\circ} \mathrm{C}\right)$. Moreover, at $1000{ }^{\circ} \mathrm{C}$, a total weight loss of $45 \mathrm{wt} \%, 62 \mathrm{wt} \%$ and $44 \mathrm{wt} \%$ respectively for 3, 6 and 9 was observed, which is comparable with that of octathiol $\mathrm{T}_{8}(64$ wt\% at the end of $\left.700{ }^{\circ} \mathrm{C}\right) .{ }^{15}$ These results confirmed the high thermal stability of these compounds inspite of the presence 
of nucleophilic thiol groups which might aid in breaking of

bonds. ${ }^{74}$ 


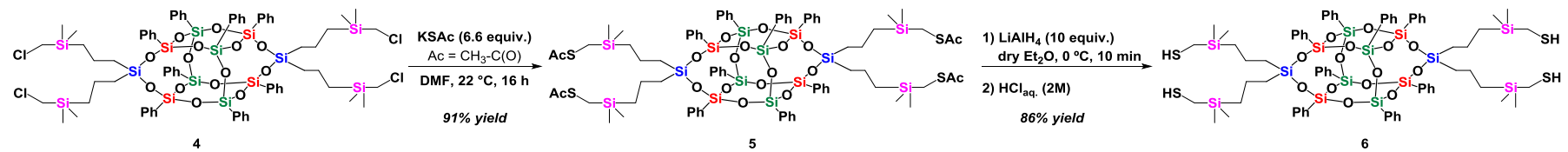

Scheme 2. Synthesis of the tetra-thiol-DDSQ 6

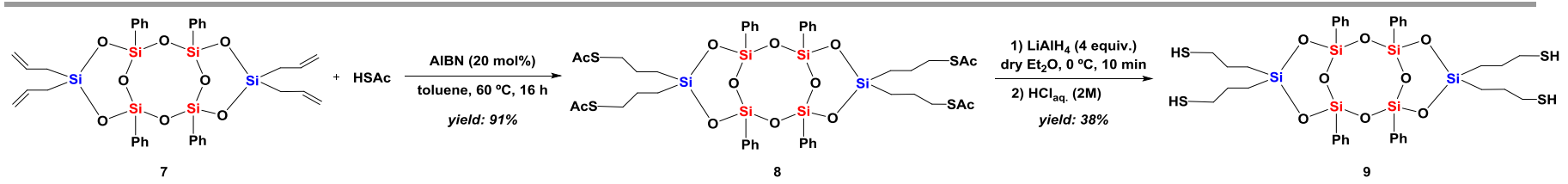

Scheme 3. Synthesis of the tetra-thiol-laddersiloxane $\mathbf{9}$

\section{Conclusions}

In this work, tetrakis(3-mercaptopropyl)-silsesquioxanes with double-decker (DDSQ) (3) or ladder (9) nano-cores were successfully prepared from the corresponding tetraallylderivatives through straightforward thiol-ene reaction with thioacetic acid and subsequent reduction. An additional tetrathiol-DDSQ with more flexible arms (6) was also synthesized from the corresponding tetrachloro-DDSQ derivative through nucleophilic substitution with potassium thioacetate followed by a reduction step. To the best of our knowledge, 3, 6 and 9 represent the first examples of welldefined functionalizable DDSQ and ladder silsesquioxanes bearing thiol reactive groups possibly further functionalized through thiol-ene reaction but also by resorting to rarely used yet also attractive and complementary thiol-yne reactions ${ }^{36,37}$ or Michael additions. ${ }^{24}$ They display significantly different topological structures than the well-described and widely used octakis-(3-mercaptopropyl)-octasilsesquioxane ( $T_{8}$-cage). With their different core structures, we believe that the three tetrathiol-silsesquioxanes reported here will present new opportunities in all the numerous areas where the related octathiol- $\mathrm{T}_{8}$-cage found applications. They thus constitute promising building blocks for the preparation of unprecedented hybrid organic-inorganic materials including cross-linked materials, ${ }^{23-48}$ challenging self-assembly systems, ${ }^{49,75}$ dendrimers or multifunctional silicon-based drug. ${ }^{66}$ It might also be possible to take advantage of the thiol groups to stabilize quantum dots or metal surfaces. ${ }^{76-77}$ Moreover, all tetrathiol- silsesquioxanes reported here displayed a very high solubility in a wide range of solvents including chloroform, dichloromethane, tetrahydrofuran, ether and toluene. Enhanced solubility is of particular importance to design optic devices for which solution-processable photoluminescent hybrid polymers are needed. ${ }^{62}$ The functionalization of compounds 3,6 and 9 to reach hybrid catalytic materials is for example currently underway in our laboratories.

\section{Conflicts of interest}

There are no conflicts to declare.

\section{Acknowledgments}

The authors acknowledge the Gunma University Initiative for Advanced Research (GIAR) for funding the Open International Laboratory and the grant to Y. L, CNRS and New Energy and Industrial Technology Development Organization (NEDO) for funding, and JASSO for M. K. travel grant to Montpellier.

\section{Notes and references}

1. D. B. Cordes, P. D. Lickiss, F. Rataboul, Chem. Rev., 2010, 110, 2081-2173.

2. Y. Du, H. Liu, Dalton Trans., 2020, 49, 5396-5405.

3. Q. Ye, H. Zhou, J. Xu, Chem. Asian J., 2016, 11, 1322-1337.

4. C. Calabrese, C. Aprile, M. Gruttadauria, F. Giacalone, Catal. Sci. Technol., 2020, 10, 7415-7447.

5. B. Dudziec, P. Zak, B. Marciniec, Polymers, 2019, 11, 504.

6. J. Wang, W. Du, Z. Zhang, W. Gao, Z. Li, J. Appl. Polym. Sci., 2021;138:e49641.

7. F. Chen, F. Lin, Q. Zhang, R. Cai, Y. Wu, X. Ma, Macromol. Rapid. Commun, 2019, 40, 1900101.

8. M. G. Mohamed, S. W. Kuo, Polymers, 2019, 11, 26.

9. H. Zhou, Q. Ye, J. Xu, Mater. Chem. Front., 2017, 1, 212.

10. A. K. Sinha, D. Equbal, Asian J. Org. Chem., 2019, 8, 32-47. 
11. P. Braunstein, J. L. Galsworthy, B. J. Hendan, H. C. Marsmann, J. Organomet. Chem., 1998, 551, 125-131.

12. H. Dang, Y. Li, H. Zou, S. Liu, Dyes and Pigments., 2020, 172, 107804.

13. Y. Xia, H. Yao, M. Cui, Y. Ma, Z. Kong, B. Wu, Z. Qi, Y. Sun, RSC Advances, 2015, 5, 80339-80345.

14. A. Kowalewska, M. Nowacka, W. Maniukiewicz, J. Organomet. Chem., 2016, 810, 15-24.

15. A. M. C. Dimitriu, M. Cazacu, A. Bargan, M. Balan, N. Vornicu, C. D. Varganici, S. Shova, J. Organomet. Chem., 2015, 799-800,195-200.

16. L. Li, S. Feng, H. Liu, RSC Advances, 2014, 4, 39132-39139.

17. K. Karuppasamy, K. Prasanna, D. Vikraman, H.-S. Kim, A Kathalingam, L. Mitu, H. W. Rhee, Polymers, 2017, 9, 192.

18. Z. Li, J. Hu, L. Yang, X. Zhang, X. Liu, Z. Wang, Y. Li, Nanoscale, 2020, 12, 11395-11415.

19. L. Liu, S. J. Lee, M. E. Lee, P. Kang, M.-G. Choi, Tetrahedron Lett., 2015, 56, 1562-1565.

20.J. K. Sierke, A. V. Ellis, Inorg. Chem. Commun., 2015, 60, 41-43.

21. D. Zhou, Y. Wang, J. Zhu, J. Yu, Z. Hu, Polymer, 2019, 167, 202-208.

22. H. Liu, R. Sun, S. Feng, D. Wang, H. Liu, Chem. Eng. J., 2019, 359, 436-445.

23. X. Wang, X. Wang, L. Song, W. Xing, G .Tang, W. Hu, Y. Hu, Thermochimica Acta, 2013, 568, 130-139.

24. B. Yu, Y. Tao, L. Liu, Y. Shi, H. Yang, G. Jie, S. Lo, Q. Tai, L. Song, Y. Hu, RSC Adv., 2015, 5, 75254-75262.

25. S. Li, S. Qiu, B. Yu, G. Tang, W. Xing, Y. Hu, RSC Adv., 2016, 6, 3025-3031.

26. L. Li, R. Liang, Y. Li, H. Liu, S. Feng, J. Colloid Interfaces Sci., 2013, 406, 30-36

27. Y. Wang, S. Ma, Y. Chen, L. Zhang, J. Ou, Y. Shen, M. Ye, Talanta, 2018, 190, 62-69.

28. H. Lin, X. Wan, X. Jiang, Q. Wang, J Yin, Adv. Funct. Mater., 2011, 21, 2960-2967.

29. J. Bai, Z. Shi, J. Yin, M. Tian, Polym. Chem., 2014, 5, 67616769.

30. B. Yu, Y. Shi, B. Yuan, L. Liu, H. Yang, Q. Tai, S. Lo, L. Song, Y. Hu, RSC Adv., 2015, 5, 13502-13506.

31. X. Bu, Y. Zhou, F. Huang, Mater. Lett., 2016, 174, 21-23.

32. J. Dai, X. Guan, H. Zhao, S. Liu, T. Fei, T. Zhang, Sensors and Actuators, 2020, 316, 128159.

33. B. Yu, X. Jiang, N. Qin, J. Yin, Chem. Commun, 2011, 47, 12110-12112.

34. Z. Xu, C. Ni, B. Yao, L. Tao, C. Zhu, Q. Han, J. Mi, Colloid. Polym. Sci., 2011, 289, 1777-1782.

35. H. Li, J. Dai, Q. Xu, C. Lu, G. Yang, F. Wang, J. Nie, X. Hu, N. Dong, J. Shi, Eur. Polym. J., 2019, 116, 74-83.

36. Y. Xu, H. Xu, X. Jiang, J. Yin, Adv. Funct. Mater., 2014, 24, 1679-1686.

37. X. Wang, D. Li, F. Yang, H. Shen, Z. Li, D. Wu, Polym. Chem., 2013, 4, 4596-4600.
38. W. Wei, Z. Xu, L. Xu, X. Zhang, H. Xiong, J. Yang, ACS Appl. Energy Mater., 2018, 1, 6769-6773.

39. Y. Xu, J. Long, R. Zhang, Y. Du, S. Guan, Y. Wang, L. Huang, H. Wei, L. Liu, Y. Huang, Polym. Degrad. Stab., 2020, 174, 109082.

40. Y. Gan, X. Jiang, J. Yin, J. Mater. Chem. C, 2014, 2, 55335539.

41. B. Wei, J. Liu, L. Ouyang, D. C. Martin, J. Mater. Chem. B, 2017, 5, 5019-5026.

42. X. Ma, F. Tao, Y. Zhang, T. Li, F. M. Raymo, Y. Cui, J. Mater. Chem. A., 2017, 5, 14343-14354.

43. J. Dai, H. Zhao, X. Lin, S. Liu, Y. Liu, X. Liu, T. Fei, T. Zhang, ACS Appl. Mater. Interfaces, 2019, 11, 6483-6490.

44. J. Dai, T. Zhang, H. Zhao, T. Fei, Sensors and Actuators $B$, 2017, 242, 1108-1114.

45. Y. Wang, S. Ma, L. Zhang, N. Zhang, Y. Li, J. Ou, Y. Shen, M. Ye, J. Sep. Sci., 2019, 42, 1332-1340.

46. A. Raghuvanshi, C. Strohman, J.-B. Tissot, S. Clément, A. Mehdi, S. Richeter, L. Viau, M. Knorr, Chem. Eur. J., 2017, 23, 16479-16483.

47. Z. Liu, J. Ou, H. Wang, L. Chen, J. Xu, M. Ye, ChemistrySelect, 2017, 2, 4538-4544.

48. S. Ma, Y. Wang, H. Zhang, Y. Li, J. Ou, Y. Wei, M. Ye, Talanta, 2019, 198, 432-439.

49. H. Chi, M. Wang, Y. Xiao, F. Wang, J. K. S, Molecules, 2018, 23, 2481.

50. W. Li, D. Wang, D. Han, R. Sun, J. Zhang, S. Feng, Polymers, 2018, 10, 917.

51. W. Li, S. Feng, J. Mol. Liq., 2018, 265, 269-275.

52. L. Li, H. Liu, Chem. Eur. J., 2016, 22, 4713-4716.

53. Y. Xia, S. Ding, Y. Liu, Z. Qi, Polymers, 2017, 9, 251-264.

54. K. Zhou, H. K. Bisoyi, J.-Q. Jin, C.-L. Yuan, Z. Liu, D. Shen, Y.-Q. Lu, Z.-G. Zheng, W. Zhang, Q. Li, Adv. Mater., 2018, 30, 1800237.

55. D. Liu, Q. Wang, W. Shen, D. Wang, J. Mater. Chem. C, 2017, 5, 103-109.

56. H. Lin, X. Wan, X. Jiang, Q. Wang, J. Yin, J. Mater. Chem., 2012, 22, 2616-2623.

57. P. Wangyang, Y. Gan, Q. Wang, X. Jiang, J. Mater. Chem. C, 2014, 2, 6140-6147.

58. Y. Gan, X. Kiang, J. Yin, Macromolecules, 2012, 45, 75207526.

59. H. Hou, Y. Gan, J. Yin, X. Jiang, Adv. Mater. Interfaces, 2014, 1, 1400385.

60. D. Liu, B. Yu, X. Jiang, J. Yin, Langmuir, 2013, 29, 53075314.

61. D. Liu, B. Yu, X. Jiang, Langmuir, 2014, 30, 7213-7220.

62. A. S. Lee, Y. Y. Jo, S.-S. Choi, K.-Y. Baek, S. S. Hwang, J. Nanosci. Nanotechnol., 2017, 5, 103-109.

63. B. Dudziec, P. Zak, B. Marciniec, Curr. Org. Chem., 2017, 21, 2794-2813.

64. Y. Liu, N. Takeda, A. Ouali, M. Unno, Inorg. Chem., 2019, 58, 4093-4098. 
65. Y. Liu, M. Kigure, K. Koizumi, N. Takeda, M. Unno, A. Ouali, Inorg. Chem., 2020, 59, 15478-15486.

66. R. Ilg, D. Troegel, C. Burschka, R. Tacke, Organometallics, 2006, 25, 548-551.

67. N. Hurkes; C. Bruhn, F. Belaj, R. Pietschnig, Organometallics, 2014, 33, 7299-7306.

68. R. Kunthom, T. Adachi, Y. Liu, N. Takeda, M. Unno, R. Tanaka, Chem. Asian. J., 2019, 14, 4179-4182.

69. V. Ervithayasuporn, T. Tomeechai, N. Takeda, M. Unno, A. Chaiyanurakkul, R. Hamkool, T. Osotchan, Organometallics, 2011, 30, 4475-4478.

70. M. Unno, A. Suto, T. Matsumoto, Russ. Chem. Rev., 2013, 82, 289-302.

71. H. Endo, N. Takeda, M. Unno, Organometallics, 2014, 33, 4148-4151.

72. Y. Liu, K. Onodera, N. Takeda, A. Ouali, M. Unno, Organometallics, 2019, 38, 4373-4378.

73. G. Sereda, S. Pothula, J. Dreessen, Synth. Commun., 2010, 40, 1312-1321.

74. C. Hartmann-Thompson, Applications of Polyhedral Oligomeric Silsesquioxanes, in: Advances in Silicon Science, Springer, vol. 3, Dordrecht Heidelberg London New York, 2011, p. 24.

75. X. Feng, S. Zhu, K. Yue, H. Su, K. Guo, C. Wesdemiotis, W.B. Zhang, S. Z. D., Y. Li, ACS Macro Lett. 2014, 3, 900-905.

76. X. Zhao, J. Du, Y. Wu, H. Liu, X. Hao, J. Mater. Chem. A, 2013, 1, 11748-11753.

77. S. Kraus-Ophir, I. Jerman, B. Orel, D. Mandler, Soft Matter, 2011, 7, 8862-8869. 